Check for updates

Cite this: Chem. Commun., 2017, 53,6903

Received 24th April 2017, Accepted 6th June 2017

DOI: $10.1039 / \mathrm{c} 7 \mathrm{cc} 03147 \mathrm{e}$

rsc.li/chemcomm

\section{The efficient synthesis and purification of amyloid- $\beta(1-42)$ using an oligoethylene glycol-containing photocleavable lysine tag $\nmid$}

\author{
John A. Karas, (D)*ab Asif Noor, ${ }^{a}$ Christine Schieber, ${ }^{a}$ Timothy U. Connell, ${ }^{a}$ \\ Frances Separovic (D) ${ }^{a}$ and Paul S. Donnelly (D) *a
}

\begin{abstract}
A short, monodisperse oligoethylene glycol-containing photocleavable lysine tag was developed to facilitate the efficient purification of hydrophobic and fibril-forming peptides. This new tag was used to prepare a modified $A \beta_{42}$ peptide with increased solubility and decreased propensity to aggregate in aqueous media. The solubilising tag was readily removed by irradiation with UV light and permitted the preparation and isolation of $A \beta_{42}$ in high purity and yield.
\end{abstract}

Alzheimer's disease is the most common form of neurodegenerative dementia. Hallmarks of the disease include extracellular plaques and intracellular tau-enriched neurofibrillary tangles in the brain. ${ }^{1,2}$ The plaques contain aggregated forms of the amyloid- $\beta(A \beta)$ polypeptide ranging in length from $39-43$ amino acid residues, formed by proteolytic cleavage of amyloid precursor protein. The two main peptides produced are $40\left(\mathrm{~A} \beta_{40}\right)$ and $42\left(A \beta_{42}\right)$ amino acid residues in length. The longer $A \beta_{42}$ has a greater propensity for aggregation in vivo and is often considered the more toxic. ${ }^{3}$ Continued efforts to better understand the structure of $\mathrm{A} \beta_{42}$ in fibrils and plaques, ${ }^{4-6}$ the toxicity of $\mathrm{A} \beta_{42}$ oligomers and assessing potential therapeutic molecules ${ }^{7}$ all require ready access to pure synthetic $A \beta_{42}$.

Solid-phase peptide synthesis (Fmoc SPPS, Fmoc $=9$-fluorenylmethoxycarbonyl) can be used to prepare $\mathrm{A} \beta_{42} .{ }^{8}$ Unfortunately, isolation of $\mathrm{A} \beta_{42}$ using conventional chromatographic techniques is extremely challenging. The propensity of $A \beta_{42}$ to aggregate results in broad and asymmetrical peaks when attempting to purify the crude peptide by high performance liquid chromatography (HPLC). This makes fractionation of the target peptide from closely-eluting peptidic impurities difficult. ${ }^{9}$

\footnotetext{
${ }^{a}$ School of Chemistry and Bio21 Molecular Science and Biotechnology Institute, The University of Melbourne, VIC 3010, Australia.

E-mail:jkaras@unimelb.edu.au, pauld@unimelb.edu.au

${ }^{b}$ Department of Chemical and Biomolecular Engineering,

The University of Melbourne, VIC 3010, Australia

$\dagger$ Electronic supplementary information (ESI) available: Experimental details of organic and peptide synthesis, purification, photolysis and aggregation studies. See DOI: $10.1039 / \mathrm{c} 7 \mathrm{cc} 03147 \mathrm{e}$
}

Several strategies have been employed to improve chromatographic peak resolution and solubility of 'difficult peptides', ${ }^{9}$ including the use of alkaline buffers to alter the net charge of the peptide $^{10}$ and high temperature HPLC. ${ }^{11}$ Temporary chemical modification of hydrophobic peptides with iso-acyl dipeptides $^{12}$ and polycationic orthogonally cleavable tags also possess effective solubilising properties in acidic media, which is typically used during RP-HPLC purifications. ${ }^{13-17}$ The addition of PEGylated or OEGylated (PEG = polyethylene glycol, OEG = oligoethylene glycol) functional groups can increase aqueous solubility over a wide $\mathrm{pH}$ range without increasing ionic charge and both are simple to incorporate during Fmoc SPPS. ${ }^{18}$ It has been shown that ortho-nitrobenzyl $(o \mathrm{Nb})$ based photocleavable protecting groups are compatible with SPPS. ${ }^{19-21}$ In this manuscript we describe a new amine-reactive, photolabile OEG tag that enhances the solubility of $\mathrm{A} \beta_{42}$ and enables its more efficient preparation.

Amine-reactive poly-disperse PEG reagents have been employed to switch on the function of proteins with light, but a small monodisperse OEG-containing substrate was considered more appropriate in this instance since a poly-disperse product would be difficult to isolate. ${ }^{22}$ It was thought that this approach may also allow some control of fibril formation. ${ }^{23}$

An $o$ Nb-based substrate containing a tert-butyloxycarbonyl (Boc) protected amino-OEG 3 chain $\left(o \mathrm{Nb}-\mathrm{OEG}_{3}\right)$ was synthesised by adapting a method of Rossi and co-workers (Scheme 1). ${ }^{24}$ Incorporation of an alkyne functional group at the benzylic position of the $o \mathrm{Nb}$ derivative via a Grignard reaction gave $1 .^{17}$ Copper(I)-catalyzed azide-alkyne cyclo-addition (CuAAC) between 1 and 2 gave 3 in a yield of $72 \%$, that was then reacted with paranitrophenyl chloroformate to produce 4 in $45 \%$ yield.

Although it would be simplest to incorporate the hydrophilic tag at the N-terminus, we chose to functionalise $\mathrm{Lys}_{28}$ due to its close proximity to the hydrophobic C-terminus that is essential for aggregation. Residues $28-42$ of $A \beta_{42}$ were assembled on the solid support by microwave-assisted Fmoc SPPS, with monomethoxytrityl (Mmt) protection at Lys $_{28}$ (Scheme 2). The $\varepsilon$-amino group was liberated after multiple treatments with dilute 
<smiles>C#CC(O)c1ccccc1[N+](=O)[O-]</smiles><smiles>CCC</smiles><smiles>CC(C)(C)OC(=O)NCCOCCOCCOCCn1cc(C(O)c2ccccc2[N+](=O)[O-])nn1</smiles>

3

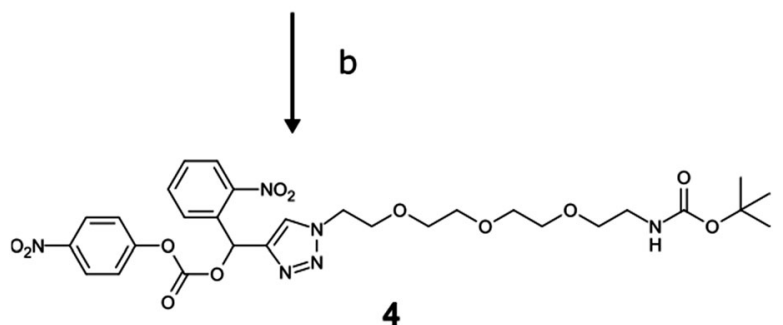

Scheme 1 Synthesis of the oNb-OEG 3 tag. (a) $\mathrm{CuSO}_{4}$, sodium ascorbate, DMF/water; (b) para-nitrophenyl chloroformate, DCM.

trifluoroacetic acid (TFA), followed by acylation with paranitrophenylcarbamate activated $o \mathrm{Nb}-\mathrm{OEG}_{3}$ at high temperature. The remainder of the peptide was assembled by SPPS, followed by global deprotection and cleavage from the solid support.

Electrospray ionisation mass spectrometry (ESI-MS) (see ESI $\dagger$ ) and analytical RP-HPLC (Fig. 1a) indicated that the target peptide was the major species present in the crude reaction mixture. The purification conditions which gave optimal peak separation were alkaline buffers at $60{ }^{\circ} \mathrm{C}$ using a C18 column. It is very difficult to analyze or purify $\mathrm{A} \beta_{42}$ with a C18 stationary phase so its use in this instance suggests that the $o \mathrm{Nb}-\mathrm{OEG}_{3}$ tag does reduce the peptide's propensity to aggregate. The presence of the solubilising tag allowed isolation of $o \mathrm{Nb}-\mathrm{OEG}_{3}-\mathrm{A}_{42}$ in excellent yield (10\%) and high purity (Fig. 1b). The solubilising OEG-tag could be readily removed by irradiation at $365 \mathrm{~nm}$ (20 min) (Fig. 2). The photolysis was performed in $80 \%$ aqueous 1,1,1,3,3,3-hexa-fluoroisopropanol (HFIP) to avoid premature aggregation prior to final purification. A shift in retention time was observed post-cleavage (Fig. 1c) as well as significant peak broadening, which is characteristic of native $A \beta_{42}$. Importantly, no significant degradation caused by the photolysis was evident and the elution profile of the target material was well resolved from non-peptidic species originating from the $o \mathrm{Nb}-\mathrm{OEG}_{3}$ tag.

The $A \beta_{42}$ peptide was purified and isolated in good yield and high purity (Fig. 1d) using semi-preparative RP-HPLC on a C4 column. The identity of the final product was confirmed by ESI-MS (see ESI $\dagger$ ). The isolated yield from the photolysis reaction was $60 \%$ after a single HPLC purification.

The presence of amyloid fibrils is often determined by monitoring the fluorescence of thioflavin- $\mathrm{T}$ (2-[ $p$-(dimethylamino)phenyl]-3,6-dimethyl-benzothiazolium chloride, ThT), which undergoes a $115 \mathrm{~nm}$ red shift in its excitation and emission profile following interaction with amyloid fibrils.

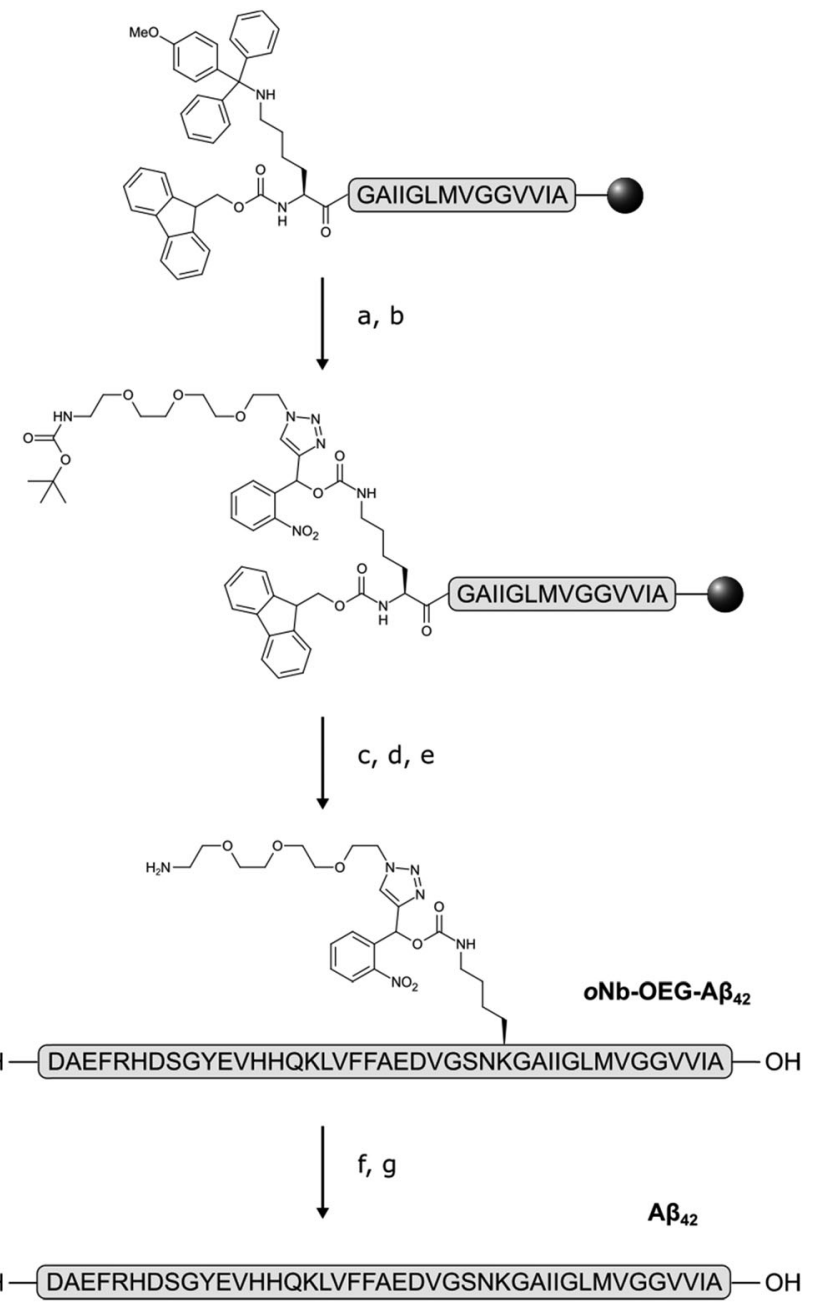

Scheme 2 Synthesis of pure amyloid- $\beta$ (1-42). (a) $10 \times 1 \%$ TFA in DCM; (b) 3 eq. 4 \& 6 eq. DIEA in DMF, $75^{\circ} \mathrm{C}, 1$ hour; (c) Fmoc SPPS; (d) $1 \%$ TIPS, $2 \%$ water, $2 \%$ thioanisole, 95\% TFA, 3 hours; (e) RP-HPLC; (f) $h \nu 365 \mathrm{~nm}$, $80 \% \mathrm{HFIP} / 20 \%$ water, $20 \mathrm{~min}$; (g) RP-HPLC.

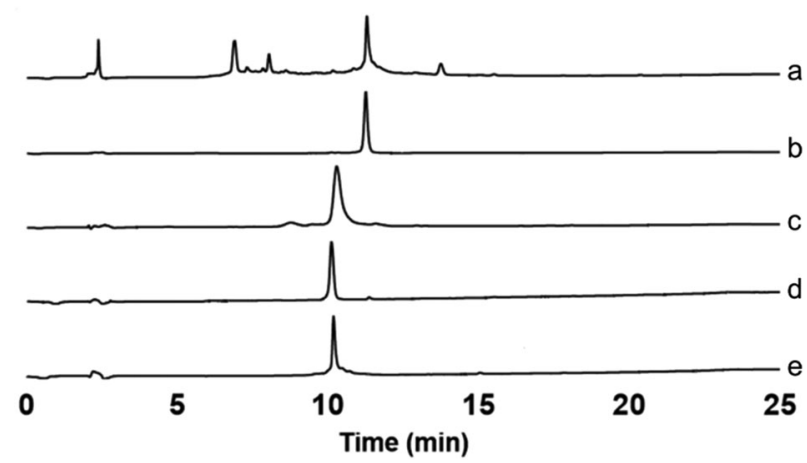

Fig. 1 Analytical RP-HPLC traces. (a) Crude oNb-OEG $-A \beta_{42}$; (b) purified oNb-OEG $-A \beta_{42}$; (c) crude (post-photolysis) $A \beta_{42}$; (d) purified (postphotolysis) $A \beta_{42}$; (e) control $A \beta_{42}$.

The presence of the solubilising tag in $A \beta_{42}$ results in less fluorescence from ThT after incubation for 48 hours when compared to a sample of native $A \beta_{42}$ prepared from the 


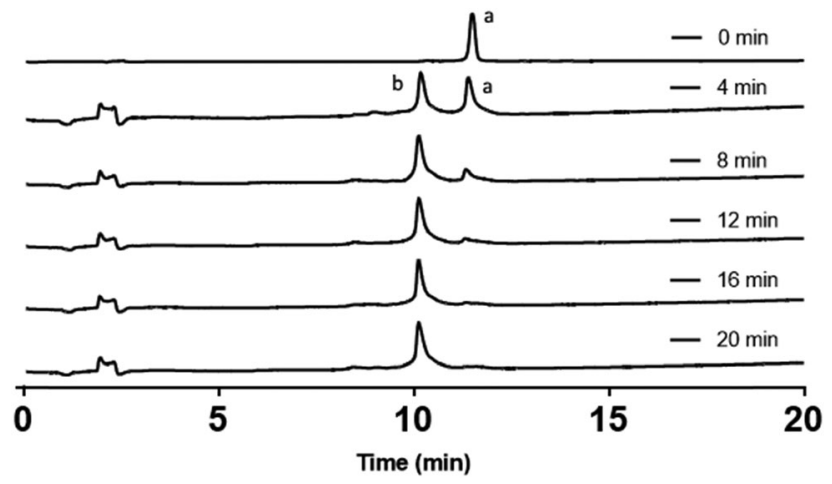

Fig. 2 Analytical RP-HPLC traces of a time course for the photolysis reaction. Peak (a) oNb-OEG-A $\beta_{42}$; peak (b) $A \beta_{42}$ obtained after photolysis of oNb-OEG-A $\beta_{42}$.

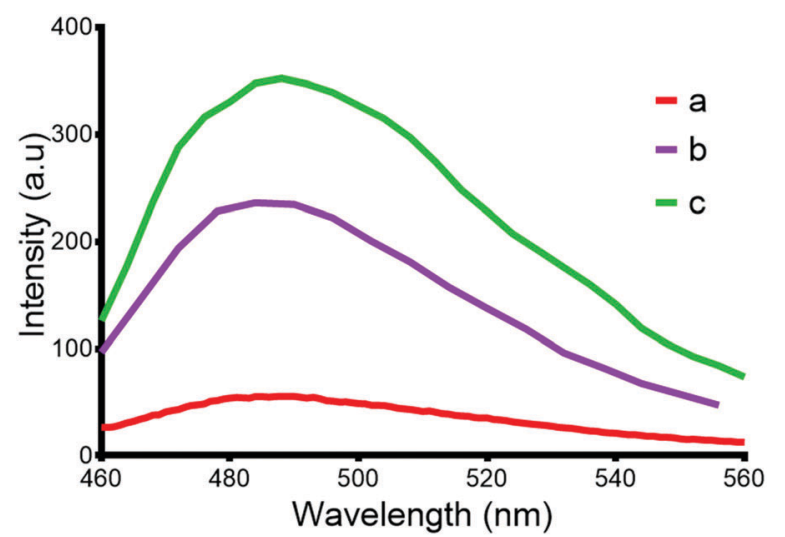

Fig. 3 ThT fluorescence curves after incubation for 48 hours at $37^{\circ} \mathrm{C}$ in PBS $\left(\lambda_{\mathrm{ex}}=444 \mathrm{~nm}\right)$. (a) ThT only in PBS; (b) oNb-OEG-A $\beta_{42}(20 \mu \mathrm{M})$; (c) $A \beta_{42}$ peptide $(20 \mu \mathrm{M})$ obtained by photolysis of oNb-OEG-A $\beta_{42}$

photolysis of $o \mathrm{Nb}-\mathrm{OEG}-\mathrm{A} \beta_{42}$ (Fig. 3). This is presumably due to the tag hindering the formation of amyloid fibrils. The structural morphology of the aggregates after photolysis of $o \mathrm{Nb}-\mathrm{OEG}-\mathrm{A} \beta_{42}$ was investigated by transmission electron microscopy (TEM), and confirmed the formation of $\mathrm{A} \beta_{42}$ fibrils (Fig. 4b). In contrast, the TEM image of $o$ Nb-OEG-A $\beta_{42}$ does not show well defined fibril structures characteristic of native peptide aggregates (Fig. 4a). Given these results, it appears that
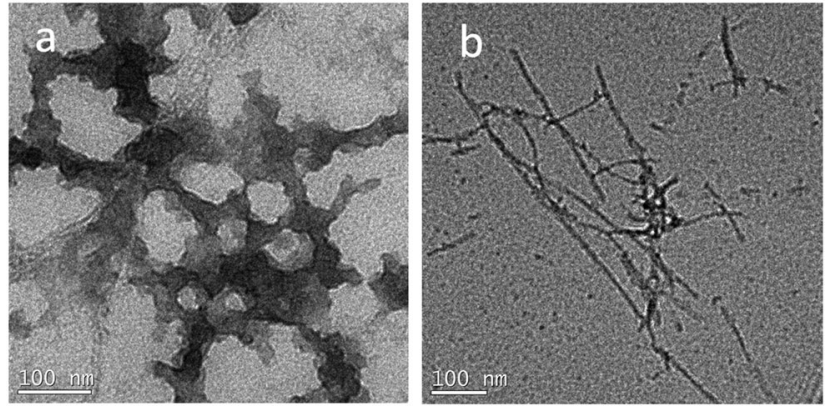

Fig. 4 TEM images after incubation for 48 hours at $37^{\circ} \mathrm{C}$ in PBS, negatively stained with $2 \%$ uranyl acetate (a) oNb-OEG-A $\beta_{42}(10 \mu M)$; and (b) $A \beta_{42}$ $(10 \mu \mathrm{M})$ prepared by photolysis of oNb-OEG-A $\beta_{42}$. strategic placement of the $o \mathrm{Nb}-\mathrm{OEG}_{3}$ tag is effective in suppressing amyloid fibril formation. This could explain why $o \mathrm{Nb}-\mathrm{OEG}-\mathrm{A} \beta_{42}$ was obtained at such a high purity.

In conclusion, a photocleavable hydrophilic tag, oNb-OEG, has been prepared and incorporated into $\mathrm{A} \beta_{42}$ at $\mathrm{Lys}_{28}$ using Fmoc SPPS. The presence of the tag improved the solubility of this hydrophobic peptide in aqueous media and suppressed the formation of aggregates and fibrils. The increased solubility enabled the synthesis and isolation of $o$ Nb-OEG-A $\beta_{42}$ in good yield and high purity. The tag could be readily removed by photolysis. It is likely that this strategy could be used for the synthesis of other hydrophobic and fibril-forming "difficult" peptides. $^{9}$

We would like to acknowledge the Australian Research Council for financial support of this research.

\section{References}

1 J. Hardy and D. Allsop, Trends Pharmacol. Sci., 1991, 12, 383-388.

2 E. Jamasbi, J. D. Wade, F. Separovic and M. A. Hossain, Curr. Med. Chem., 2016, 23, 884-892.

3 M. Citron, Nat. Rev. Drug Discovery, 2010, 9, 387-398.

4 M. T. Colvin, R. Silvers, Q. Z. Ni, T. V. Can, I. Sergeyev, M. Rosay, K. J. Donovan, B. Michael, J. Wall, S. Linse and R. G. Griffin, J. Am. Chem. Soc., 2016, 138, 9663-9674.

5 N. J. Economou, M. J. Giammona, T. D. Do, X. Zheng, D. B. Teplow, S. K. Buratto and M. T. Bowers, J. Am. Chem. Soc., 2016, 138, 1772-1775.

6 Y. Xiao, B. Ma, D. McElheny, S. Parthasarathy, F. Long, M. Hoshi, R. Nussinov and Y. Ishii, Nat. Struct. Mol. Biol., 2015, 22, 499-505.

7 D. J. Hayne, S. Lim and P. S. Donnelly, Chem. Soc. Rev., 2014, 43, 6701-6715.

8 E. Atherton, C. J. Logan and R. C. Sheppard, J. Chem. Soc., Perkin Trans. 1, 1981, 538-546.

9 M. Paradís-Bas, J. Tulla-Puche and F. Albericio, Chem. Soc. Rev., 2015, 45, 631-654.

10 W. M. Kok, J. M. Cottam, G. D. Ciccotosto, L. A. Miles, J. A. Karas, D. B. Scanlon, B. R. Roberts, M. W. Parker, R. Cappai, K. J. Barnham and C. A. Hutton, Chem. Sci., 2013, 4, 4449.

11 G. Vanhoenacker and P. Sandra, Anal. Bioanal. Chem., 2008, 390, 245-248.

12 T. Yoshiya, A. Taniguchi, Y. Sohma, F. Fukao, S. Nakamura, N. Abe, N. Ito, M. Skwarczynski, T. Kimura, Y. Hayashi and Y. Kiso, Org. Biomol. Chem., 2007, 5, 1720.

13 M. A. Hossain, A. Belgi, F. Lin, S. Zhang, F. Shabanpoor, L. Chan, C. Belyea, H.-T. Truong, A. R. Blair, S. Andrikopoulos, G. W. Tregear and J. D. Wade, Bioconjugate Chem., 2009, 20, 1390-1396.

14 J.-S. S. Zheng, Y. He, C. Zuo, X.-Y. Y. Cai, S. Tang, Z. A. Wang, L.-H. H. Zhang, C.-L. L. Tian and L. Liu, J. Am. Chem. Soc., 2016, 138, 3553-3561.

15 M. T. Jacobsen, M. E. Petersen, X. Ye, M. Galibert, G. H. Lorimer, V. Aucagne and M. S. Kay, J. Am. Chem. Soc., 2016, 138, 11775-11782.

16 C. Zuo, S. Tang, Y.-Y. Y. Si, Z. A. Wang, C.-L. L. Tian and J.-S. S. Zheng, Org. Biomol. Chem., 2016, 14, 5012-5018.

17 S. Chemuru, R. Kodali and R. Wetzel, Biopolymers, 2014, 102, 206-221.

18 R. V. Pillai and M. Mutter, Acc. Chem. Res., 1981, 14, 122-130.

19 P. Klán, T. Šolomek, C. G. Bochet, A. Blanc, R. Givens, M. Rubina, V. Popik, A. Kostikov and J. Wirz, Chem. Rev., 2013, 113, 119-191.

20 N. Kotzur, B. Briand, M. Beyermann and V. Hagen, J. Am. Chem. Soc., 2009, 131, 16927-16931.

21 J. A. Karas, D. B. Scanlon, B. E. Forbes, I. Vetter, R. J. Lewis, J. Gardiner, F. Separovic, J. D. Wade and M. A. Hossain, Chem. Eur. J., 2014, 20, 9549-9552.

22 W. E. Georgianna, H. Lusic, M. L. Andrew and A. Deiters, Bioconjugate Chem., 2010, 21, 1404-1407.

23 Y. Sohma, Y. Hayashi, M. Kimura, Y. Chiyomori, A. Taniguchi, M. Sasaki, T. Kimura and Y. Kiso, J. Pept. Sci., 2005, 11, 441-451.

24 J. A. Baccile, M. A. Morrell, R. M. Falotico, B. T. Milliken, D. L. Drew and F. M. Rossi, Tetrahedron Lett., 2012, 53, 1933-1935. 